\title{
Preparing for a COVID-19 pandemic: a review of operating room outbreak response measures in a large tertiary hospital in Singapore
}

\section{Se préparer pour la pandémie de COVID-19: revue des moyens déployés dans un bloc opératoire d'un grand hôpital tertiaire au Singapour}

\author{
Jolin Wong, MBBS, MMed (Anaes), FANZCA (1) • Qing Yuan Goh, MBBS, MMed (Anaes), EDIC ( • • \\ Zihui Tan, MB ChB, MMed (Anaes) • Sui An Lie, MBBS, MRCP, MMed (Anaes) (1) • \\ Yoong Chuan Tay, MBBS, MMed (Anaes) - Shin Yi Ng, MBBS, MMed (Anaes), EDIC, PGDip (Clinical Ultrasound), \\ FCCP, FCCM, FAMS • Chai Rick Soh, MBBS, MMed (Anaes), FANZCA, CICM
}

Received: 2 March 2020/Revised: 4 March 2020/Accepted: 4 March 2020/Published online: 11 March 2020

(C) Canadian Anesthesiologists' Society 2020

\begin{abstract}
The coronavirus disease 2019 (COVID-19) outbreak has been designated a public health emergency of international concern. To prepare for a pandemic, hospitals need a strategy to manage their space, staff, and supplies so that optimum care is provided to patients. In addition, infection prevention measures need to be implemented to reduce in-hospital transmission. In the operating room, these preparations involve multiple stakeholders and can present a significant challenge. Here, we describe the outbreak response measures of the anesthetic department staffing the largest (1,700-bed) academic tertiary level acute care hospital in Singapore (Singapore General Hospital) and a smaller regional hospital (Sengkang General Hospital). These include engineering controls such as identification and preparation of an isolation operating room, administrative measures such as modification of workflow and processes, introduction of personal protective equipment for staff, and formulation of clinical guidelines for anesthetic management. Simulation was valuable in evaluating the feasibility of new operating room set-ups or
\end{abstract}

JolinWong, MBBS, MMed (Anaes), FANZCA ( $\square)$.

Q. Y. Goh, MBBS, MMed (Anaes), EDIC - Z. Tan, MB ChB, MMed (Anaes) - S. A. Lie, MBBS, MRCP, MMed (Anaes) ·

Y. C. Tay, MBBS, MMed (Anaes) · S. Y. Ng, MBBS, MMed (Anaes), EDIC, PGDip (Clinical Ultrasound), FCCP, FCCM, FAMS - C. R. Soh, MBBS, MMed (Anaes), FANZCA, CICM Division of Anaesthesiology, Singapore General Hospital, Outram Road, Singapore 169608, Singapore

e-mail: jolin.wong@singhealth.com.sg workflow. We also discuss how the hierarchy of controls can be used as a framework to plan the necessary measures during each phase of a pandemic, and review the evidence for the measures taken. These containment measures are necessary to optimize the quality of care provided to COVID-19 patients and to reduce the risk of viral transmission to other patients or healthcare workers.

Résumé L'épidémie liée au coronavirus 2019 (COVID-19) a été qualifiée d'urgence de santé publique de portée internationale. La préparation face à une pandémie nécessite de la part d'un hôpital l'élaboration de stratégies pour gérer ses infrastructures, ses processus, son personnel et ses patients; il doit notamment instaurer des mesures de prévention des infections pour réduire la transmission intrahospitalière. Pour un bloc opératoire, ces préparations impliquent la participation de nombreux acteurs et peuvent constituer un véritable défi. Nous décrivons les mesures prises en réponse à l'épidémie par le département d'anesthésie qui sert le plus grand hôpital universitaire de soins aigus (1700 lits) de Singapour (Singapore General Hospital) et un plus petit hôpital régional (Sengkang General Hospital). Cela a été obtenu grâce à des expertises d'ingénierie, telles que l'identification et la préparation d'une salle d'opération en isolation, des mesures administratives telles que la modification du déroulement des activités et des processus, l'introduction d'équipements de protection individuels pour le personnel et - enfin - la formulation de lignes directrices cliniques pour la gestion anesthésique. La 
simulation a été importante pour évaluer la faisabilité de toutes nouvelles modifications des salles d'opération ou d'un nouveau flux de travail. Dans le contexte des différentes phases d'une pandémie, nous discutons de l'application d'une hiérarchie de contrôles comme cadre des modifications à chaque niveau de contrôle et nous passons aussi en revue les données probantes soutenant les mesures prises. Ces mesures de confinement sont nécessaires pour optimiser la qualité des soins procurés aux patients atteints de COVID-19 et pour réduire le risque de transmission du virus à d'autres patients ou employés du domaine de la santé.

On 30 January 2020, the World Health Organization (WHO) declared the severe acute respiratory syndrome coronavirus 2 (SARS-CoV-2) outbreak a public health emergency of international concern. ${ }^{1}$ Human-to-human transmission of SARS-CoV-2 was established and at the time of writing this article, it has caused coronavirus disease (COVID-19) in over 90,000 people in 72 countries, with a case fatality rate of $2.3 \%$ in China and $1.6 \%$ outside China. $^{2-8}$

Singapore General Hospital (SGH) confirmed Singapore's first case of COVID-19 on 23 January 2020. ${ }^{9,10}$ Local transmission was subsequently reported ${ }^{11}$ and by 7 February 2020, Singapore raised the Disease Outbreak Response System Condition (DORSCON) alert level to orange, indicating that the disease is severe and spreads easily from person to person (but is not spread widely and is being contained). ${ }^{12,13}$

Current understanding of SARS-CoV2 transmission is based on extrapolation from past experience with the SARS-CoV outbreak in 2003. ${ }^{14-17}$ Possible modes of transmission include respiratory droplets, contact, fomites, and the fecal-oral route. ${ }^{18,19}$ At present, there is no conclusive evidence of airborne transmission of SARSCoV-2, but past experience suggests that SARS-CoV can be transmitted via aerosol-generating procedures, most commonly tracheal intubation. ${ }^{20,21}$ As with most respiratory viruses, it is considered most contagious when the patient is symptomatic, but SARS-CoV-2 has been transmitted by asymptomatic individuals. ${ }^{22}$ Early data suggests that transmissibility of SARS-CoV-2 is moderate, with a basic reproduction number of approximately $2 .^{23,24}$

Transmission within healthcare facilities to healthcare workers has been documented: $3.8 \%$ of COVID-19 cases have occurred in healthcare workers, causing five deaths in
China. ${ }^{7}$ During the SARS outbreak in 2003, anesthesiologists also contracted SARS in the line of duty. ${ }^{25}$ With the institution of infection control measures, several hospitals successfully operated on patients with SARS without any transmission of SARS-CoV within the operating room complex. ${ }^{26,27}$

The Division of Anesthesiology at SGH developed disease outbreak response measures in coordination with surgical, nursing, and other allied health staff. The two goals of these measures were to facilitate the care of patients with known or suspected COVID-19 who needed surgery, and to reduce the risk of perioperative viral transmission to healthcare workers and other patients. At the time of writing, no patients with COVID-19 have required surgery, but we expect this to change in the near future as the number of cases increases globally.

This article aims to describe the measures taken to address these goals, including identification and set-up of an isolation operating room (OR), modification of workflow and processes, management of staff, and formulation of clinical guidelines for anesthetic management.

\section{Hospital measures related to surgery and anesthesia}

Increasing capacity

To cope with the anticipated increased influx of COVID-19 patients, we decided to reduce elective surgery. ${ }^{28}$ Day surgery, cancer surgery, and other urgent operations continued as normal. We increased the turnaround time between elective surgeries to accommodate additional infection prevention measures.

Management of patients, visitors, and staff

All patients presenting to the hospital were screened using a standard questionnaire. Patients who fulfilled the criteria for suspected SARS-CoV-2 infection were isolated, referred to an infectious diseases specialist, and tested for the virus. Elective surgery was postponed if the patient had travelled to affected areas. Visitor numbers were also restricted. $^{28}$

Staff were asked to refrain from unnecessary travel to certain destinations as advised by the Singapore Ministry of Health. ${ }^{29}$ Staff returning from these destinations were required to take a 14-day leave of absence. We also separated staff caring for COVID-19 patients and those caring for other patients to reduce the risk of in-hospital 
transmission. Staff who had cared for COVID-19 patients continued with usual clinical work with a surgical mask on and monitored themselves for fever and respiratory symptoms. If inadequate personal protective equipment (PPE) was worn at the time of close contact, the staff member was taken off duty while an infectious diseases team assessed the risk of transmission and planned subsequent management. Temperatures of all staff were taken twice daily using hospital-issued oral digital thermometers, and entered into electronic records monitored by administrative personnel. Web-based forms were created to facilitate ease of entry using personal smartphones. Staff members who developed a fever or respiratory symptoms were screened at the staff clinic.

\section{Communications and staff support}

In the early phase of the outbreak, the situation was rapidly evolving so case definitions and hospital guidelines were modified frequently. Communication channels including a COVID-19 website were set up and daily email updates were sent to all staff. Staff used social media, such as Workplace from Facebook and encrypted instant messaging, to approach senior management with ideas or concerns. $^{13}$

Resources, including reading material and a helpline, were set up in the hospital to help staff cope with COVID19-related anxiety and burnout. ${ }^{13}$
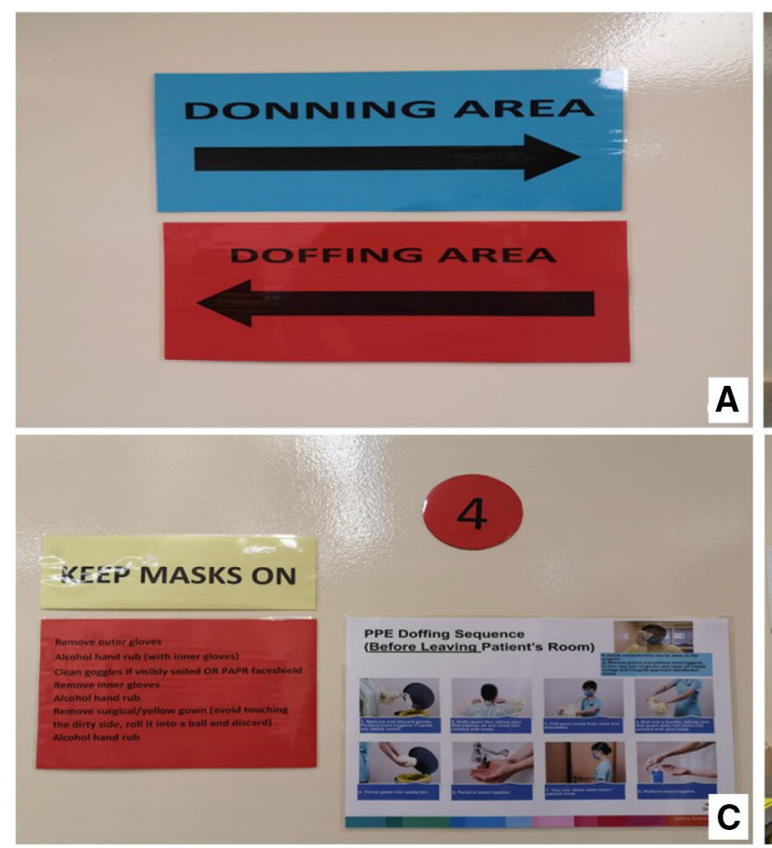

Fig. 1 Personal protective equipment donning and doffing areas. Steps are colour-coded (A: blue for clean and red for contaminated) and marked in numerical sequence at designated areas just outside the OR, with posters to guide staff on the process. Step 1: Put on N95.

\section{Operating room management}

An OR with a negative pressure environment is ideal to reduce dissemination of the virus beyond the OR. ${ }^{5,30} \mathrm{~A}$ standard OR is usually designed to be at positive pressure relative to surrounding air. Nevertheless, a high frequency of air changes ( 25 per hr) rapidly reduces viral load within the OR.

A small OR complex comprising three separate ORs was designated for surgery in patients suspected or confirmed to have COVID-19. This was separate from the main OR complex and reduced the risk of contaminating other ORs and other patients. Elective surgeries on non-COVID-19 patients were relocated to the main OR complex. Each OR had its own ventilation system with an integrated high-efficiency particulate air (HEPA) filter. Traffic and flow of contaminated air were minimized by locking all doors to the OR during surgery, with only one possible route for entry/exit via the scrub room.

New workflows were created for activation and use of the designated isolation OR. These workflows considered coordination of staff, movement of surgical and anesthetic equipment, infection prevention practices, and decontamination following the procedure. An additional anesthesiologist was called in to care for the COVID-19 patient, while the usual on-call specialist continued with emergency surgery in the main OR.
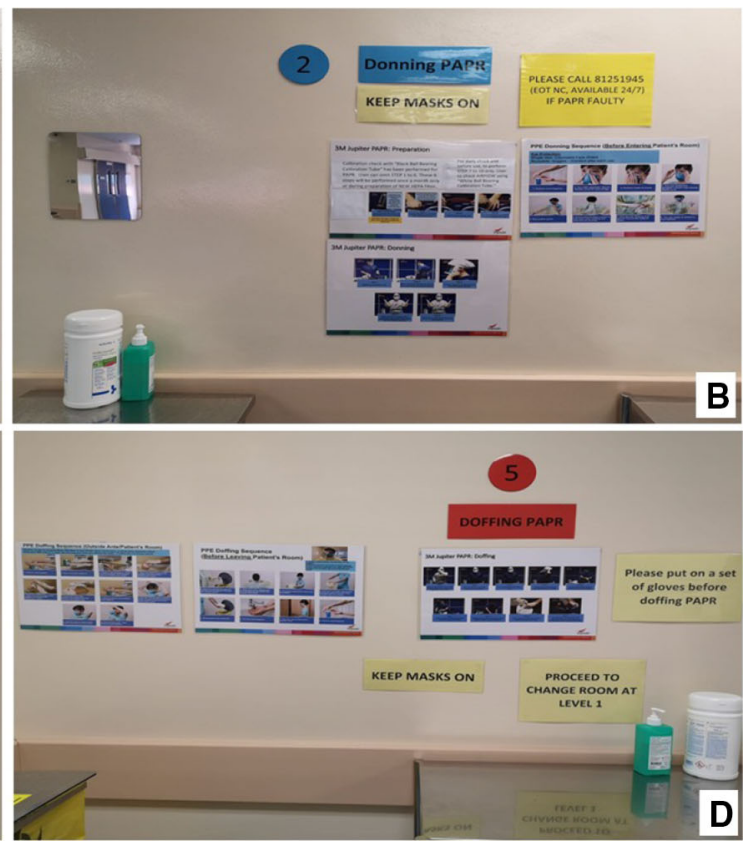

Step 2: Donning PAPR (B). Step 3: Enter OR through scrub room. Step 4: Clean external surface of the PAPR face shield (C), remove surgical gown and outer gloves. Step 5: Doffing PAPR (D). OR = operating room; PAPR $=$ powered air-purifying respirator 
Because more time is needed to prepare for surgery in a suspected/confirmed case of COVID-19, daily routines were set up regardless of whether surgery would happen. These included routine checks and cleaning of anesthetic machines and powered air-purifying respirator (PAPR) sets. Designated areas were prepared for donning and doffing of PPE. Steps were numbered in sequence and posters were put up to guide staff (Fig. 1).

\section{Management of staff in the division of anesthesiology}

Personal protective equipment

A comprehensive program for the use of PPE was enforced. Healthcare personnel were medically cleared and trained in the use of PPE. They were also taught how to clean, disinfect, store, and inspect their PPE for any damage. All staff were fitted with the National Institute of Occupational Safety and Health (NIOSH)-certified N95 respirators. If staff did not fit into available N95 masks, they would use the CleanSpace ${ }^{\mathrm{R}}$ $\mathrm{HALO}^{\mathrm{TM}}$ PAPR (CleanSpace Technology Pty Ltd, Artarmon, NSW, Australia). Personal goggles (model 9302245; Uvex, Germany) were also issued to every member of staff.

\section{Powered air-purifying respirator training}

Refresher training for the use and maintenance of the PAPR was conducted. Educators from the Department of Occupational and Environmental Medicine trained designated trainers within the department who then went on to train the 180 anesthesia staff members (consultants and trainees) on the Jupiter and Proflow PAPR models (3M, St Paul, MN, United States of America). In addition, mask fitting was done for all users of the CleanSpace ${ }^{\mathrm{R}} \mathrm{HALO}^{\mathrm{TM}}$.

\section{Segregation of staff}

The anesthesia division staffs a tertiary hospital (SGH) and a smaller regional hospital (Sengkang General Hospital). Staff were segregated between the two to reduce cross infection between hospitals. Locum employment and large group meetings were suspended. Web-based conferencing was used to enable communication. Attendance was taken at all face-toface meetings to facilitate contact tracing should the need arise.

\section{Minimizing exposure and spread}

Routine postoperative visits were suspended and replaced by phone calls where applicable to reduce movement of staff around the hospital. Non-urgent preoperative assessment clinic visits were also postponed. Pregnant and immunocompromised staff did not care for patients with COVID-19.

\section{Measures for infection prevention}

Routine infection prevention measures

Once community spread of the virus had been confirmed, the hospital instituted guidelines for airborne and contact precautions during all aerosol-generating procedures. These included wearing N95 masks, eye protection, gown, and gloves. Routine care of low-risk patients (no fever or respiratory symptoms, no history of recent travel or close contact with a COVID-19 patient) required only the use of a simple surgical mask to protect against droplet transmission.

Infection prevention when caring for the COVID-19 patient

The minimum standard of PPE for any staff caring for a patient with confirmed/suspected COVID-19 infection is a fitted, NIOSH-certified N95 respirator, eye protection (either goggles or full-face shield), cap, gown, and gloves. ${ }^{5}$ Double gloves may be considered and the outer pair should be changed when contaminated. ${ }^{31}$ As transmission remains possible despite N95 protection, ${ }^{32}$ staff participating in aerosol-generating procedures can wear a PAPR (Fig. 2).

The patient, wearing a surgical face mask, should be transported from the isolation unit along a designated route with minimal contact with others. ${ }^{31}$

Only selected equipment and drugs should be brought into the OR to reduce the number of items that need cleaning or discarding following the procedure. ${ }^{33}$ Singleuse equipment should be selected where possible. ${ }^{26}$ Consent and charting are done electronically with touchscreen devices to facilitate decontamination. Anesthetic monitors, laptop computers, and ultrasound machine surfaces are covered with plastic wrap to decrease the risk of contamination and to facilitate cleaning (Fig. 3).

The patient should be reviewed, induced, and recovered within the OR itself to restrict contamination to just one room. ${ }^{27}$ The number of staff involved in the surgery should be limited. ${ }^{5}$ Movement of staff in and out of the OR should also be restricted. ${ }^{31}$

After surgery, the anesthetic breathing circuit and the canister of soda lime are discarded to eliminate the negligible risk of circuit contamination. ${ }^{25,26,34}$ After disposing of singleuse equipment in well-marked biohazard bags, all instruments are sent for decontamination and sterile reprocessing. Surfaces of all medical devices are cleaned with quaternary ammonium chloride disinfectant wipes. The OR is then 
Fig. 2 Staff in powered airpurifying respirator (PAPR) during an aerosol-generating procedure

Fig. 3 High-touch equipment within the operating room are wrapped with plastic sheets to facilitate decontamination. A) Anesthesia workstation. B) Back of anesthesia workstation. C) Exposed surfaces wrapped with plastic. D) Laptop for nursing documentation
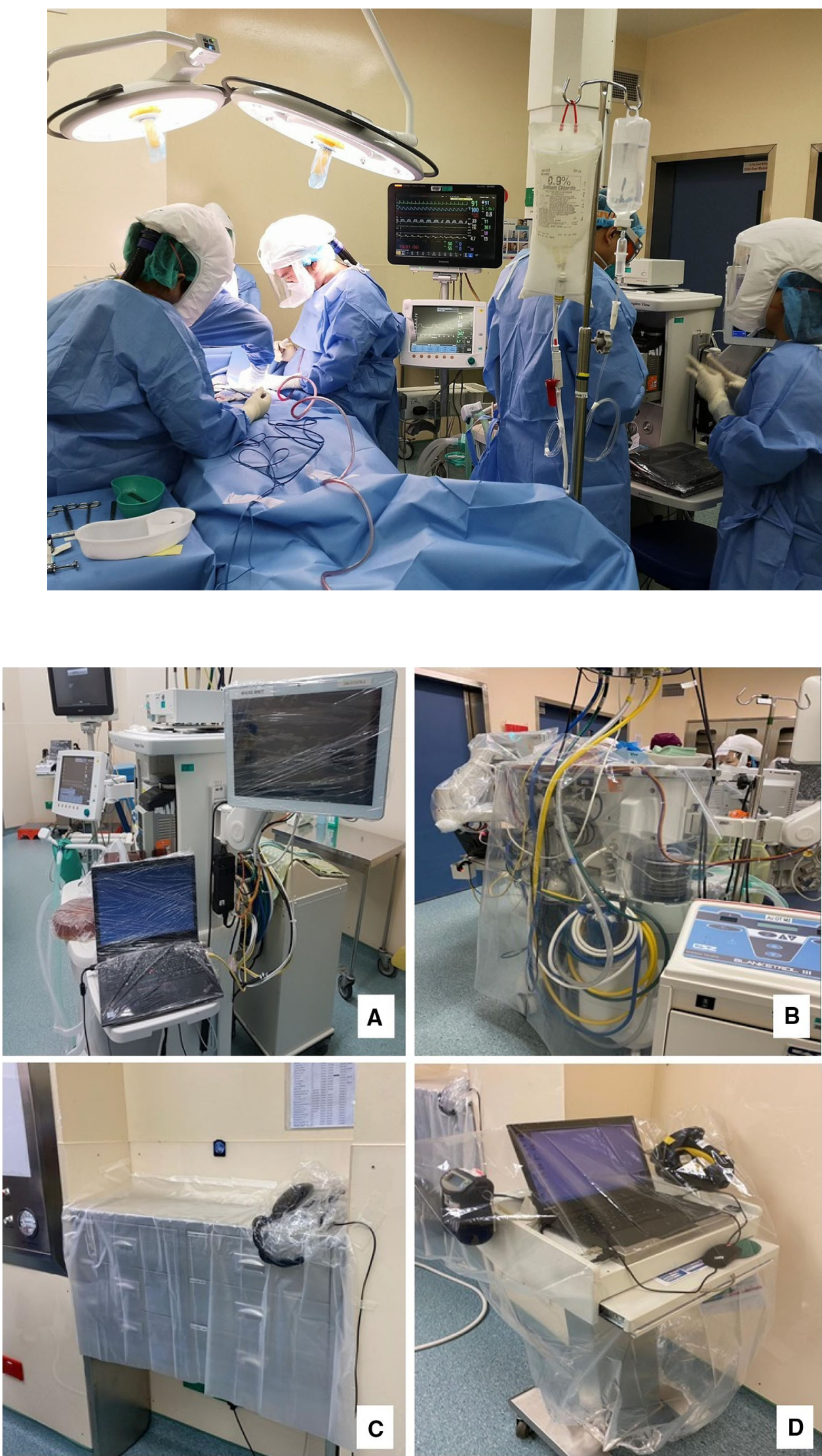
cleaned with sodium hypochlorite $1000 \mathrm{ppm}$ and treated with hydrogen peroxide vaporization or ultraviolet- $\mathrm{C}$ irradiation. All staff then shower and change into a clean set of scrubs. Names of all participating staff members are recorded to facilitate contact tracing. More time is needed for decontamination, so the turn-around time following surgery is increased.

\section{Anesthesia of patients with suspected/confirmed COVID-19}

A study of 1,099 patients with COVID-19 showed that $18.7 \%$ present with shortness of breath, $41.3 \%$ require oxygen supplementation, $5 \%$ become critically ill, and $2.3 \%$ require invasive mechanical ventilation. ${ }^{35}$ The median duration of symptoms and hospital length of stay are both between 12 and 13 days. ${ }^{10,35}$ To reduce risks to both patient and staff, only emergency and not elective surgery should be performed on COVID-19-infected patients. ${ }^{33}$ If a few hours' delay is permissible, it is preferable to await the results of the viral swab before proceeding. In patients confirmed to have COVID-19 who require urgent surgery (e.g., cancer or cardiac surgery), the risks and benefits of proceeding or postponing need to be weighed.

A team huddle should take place before surgery to ensure everyone understands the plan for anesthesia and surgery. This enables seamless teamwork and ensures that all necessary drugs and equipment have been prepared. It also minimizes the need to leave and re-enter the OR to bring in missing equipment. All staff should be aware that communication is more difficult after PPE (and especially PAPR) have been donned, and pay special attention to facilitate communication during the procedure. ${ }^{26}$ All staff should be protected in appropriate PPE, and the staff number should be restricted to the minimum necessary for patient safety. ${ }^{5}$ Given the relative lack of familiarity with the new changes in workflow, an OR coordinator is assigned to each team caring for the COVID-19 patient. This coordinator directs all team members and guides them on their roles and infection prevention measures. A core group of anesthesiologists, who are familiar with the isolation OR processes, serve as coordinators.

Anesthesia should be planned with two goals in mind: patient safety and infection prevention. Infection prevention entails reducing aerosol-generating procedures (i.e., airway manipulation, face mask ventilation, open airway suctioning, patient coughing) as far as possible. ${ }^{33}$ Regional anesthesia is preferred over general anesthesia. Awake intubation techniques should be avoided because both patient coughing and atomized local anesthetic may lead to aerosolization of the virus..$^{25,33}$ If a regional technique is chosen, the patient should wear a surgical face mask at all times. ${ }^{5}$ If sedation is administered, supplemental oxygen may be administered via nasal prongs underneath the surgical mask. ${ }^{25}$ Non-invasive positive pressure ventilation and high flow nasal cannulae such as the transnasal humidified rapid-insufflation ventilatory exchange should be avoided to reduce the risk of viral aerosolization.

Before anesthesia induction, a HEPA filter should be connected to the patient end of the breathing circuit, and another between the expiratory limb and the anesthetic machine. ${ }^{33}$ Equipment should be prepared to reduce the need for circuit disconnections-e.g., any circuit extensions should be attached before starting the case. A definitive airway with an endotracheal tube is preferred over a supraglottic airway device because it has a better seal. A video-laryngoscope is recommended because a PAPR hood or goggles may hamper vision during direct laryngoscopy. A video-laryngoscope also keeps the intubator further from the patient's airway during intubation. $^{36}$

Pre-oxygenation should be carried out via a well-fitting face mask. ${ }^{25}$ Rapid sequence induction should be carried out to reduce the need for bag-mask ventilation. ${ }^{25}$ If bagmask ventilation cannot be avoided, small tidal volumes (at low pressure) should be administered. ${ }^{25}$ Deep anesthesia and neuromuscular blockade should be achieved before attempting intubation, and the latter can be assessed by train-of-four monitoring. Ensure full expiration into the face mask before lifting it off the patient's face. The most experienced operator should intubate. ${ }^{25}$ Following intubation, the cuff should be inflated and the circuit connected before initiating positive pressure ventilation. Closed, in-line tracheal suction should be used instead of open suction. ${ }^{33}$ Minimizing circuit disconnections is ideal, but if this is unavoidable, ensure positive pressure ventilation is ceased, turn the adjustable pressure limiting valve to zero, and consider clamping the endotracheal tube prior to disconnection. This technique may also be used before switching a patient from intensive care from the transport ventilator to the anesthetic machine. The patient should be preoxygenated and the duration of disconnection should be kept to a minimum to avoid exacerbating hypoxia in critically ill COVID-19 patients with respiratory failure.

Anti-emetics should be administered to reduce postoperative retching. A rigid suction catheter may be used to reduce the chance of contaminating the surroundings with the soft flexible suction catheter. All equipment in contact with patient secretions should be carefully manipulated. This includes the suction device, endotracheal tube, nasogastric tube (if used) and even the tape used to cover the eyes. Following extubation, the 
patient should wear a surgical face mask. Supplemental oxygen may be administered via nasal prongs underneath the face mask. ${ }^{25}$ Venturi masks should be avoided as they may aerosolize the virus. ${ }^{25}$ The patient should recover within the OR itself.

\section{Considerations specific to individual disciplines}

Interventional radiology (IR)

As far as possible, portable cases that can be done under local anesthesia should be done so in the isolation ward within the airborne infection isolation room (AIIR) ${ }^{28}$ If the procedure requires anesthetic support, it should take place in the isolation OR. If the procedure is more complex and requires specialized equipment such as a computed tomography scan, it should take place in a dedicated room within the IR facility with its own control room.

As the IR suite is regularly used for procedures, it would have to be cleared and prepared for a patient with COVID19. This would mean postponing or cancelling other elective procedures and discharging any patients recovering within the post-anesthetic care unit. Unnecessary equipment should be removed from the procedure room. Remaining equipment (such as image intensifier, lead shield) should be covered with plastic sheets. Signs are placed at doors to alert other staff not to enter the room without PPE.

A similar workflow can be replicated as in the isolation OR with similar principles of reducing exposure of staff, ensuring appropriate PPE, reducing contamination, and subsequent decontamination. All processes from preinduction checks to recovery should be done within the procedure room. ${ }^{27}$

\section{Obstetrics}

Current limited evidence suggests that there is no vertical transmission of the virus to the neonate if the mother is infected in late pregnancy. ${ }^{37}$ Considerations specific to obstetrics include protecting the neonate and preventing transmission of the virus. In theory, a lower segment Cesarean delivery may reduce fecal-oral transmission, but this is may not be favoured because it has more risks. ${ }^{38}$

Cesarean deliveries should be performed in the isolation OR if the mother is a known or suspected COVID-19 patient. At birth, the neonate should be isolated and be cared for by a dedicated neonatal team in a separate room from the mother. ${ }^{38,39}$ We use the induction room for this purpose as it has the necessary oxygen supply and suction apparatus. If this environment is unfamiliar to obstetric and neonatal teams, simulation is conducted to familiarize all the staff with the planned workflow.

\section{Cardiothoracic surgery}

The National Heart Centre Singapore (NHCS) performs all elective cardiac surgery within its own OR complex, which is connected to the main SGH building via a link bridge. Emergency surgeries done after office hours are usually performed in the major OR complex in the main SGH building. To isolate known/suspected COVID-19 patients requiring emergency cardiac surgery, the largest OR within the outbreak OR complex was chosen. This accommodated additional equipment such as the cardiopulmonary bypass machine, intra-aortic balloon pump, transesophageal echocardiography machine, and fluid management system. Because the main NHCS operating complex was further away, equipment such as a dedicated bypass machine and other essential cardiac equipment such as cell saver, cerebral oximetry, fluid warmer, and disposable bronchoscope were stored in the isolation OR complex. The use of a heated humidifier was discouraged to avoid viral aerosolization.

Equipment kits for peripheral arterial and central venous cannulation were assembled and contained all necessary items such as syringes and gauze (Fig. 4). This was done to reduce contamination of common equipment stores. To familiarize cardiothoracic anesthetic staff with the new setup in the isolation $\mathrm{OR}$, they were given photographs showing the location of essential drugs and equipment.

\section{In situ simulation}

In situ simulation was important for testing the preparedness of our isolation OR and procedures. In situ simulation is simulation training that takes place in the actual clinical environment. It has been used to improve reliability and safety in high-risk or high-stress environments, ${ }^{40-42}$ and has been shown to improve clinical skills, teamwork, patient safety, and behaviour. ${ }^{43}$ We conducted a series of simulations and "walk-throughs" of various scenarios with different surgical disciplines. The final scenario involved a crisis situation that required the surgical and anesthesia participants to perform resuscitation while wearing PPEs and PAPRs. The objectives of these simulations were to proactively seek latent threats and potential breaches in infection control, especially during vulnerable and stressful moments of crisis. We also wanted to evaluate the responsiveness of our activation workflow and adaptability of the isolation OR to cater to a variety of surgeries. These simulation exercises allowed us to identify and address unexpected 


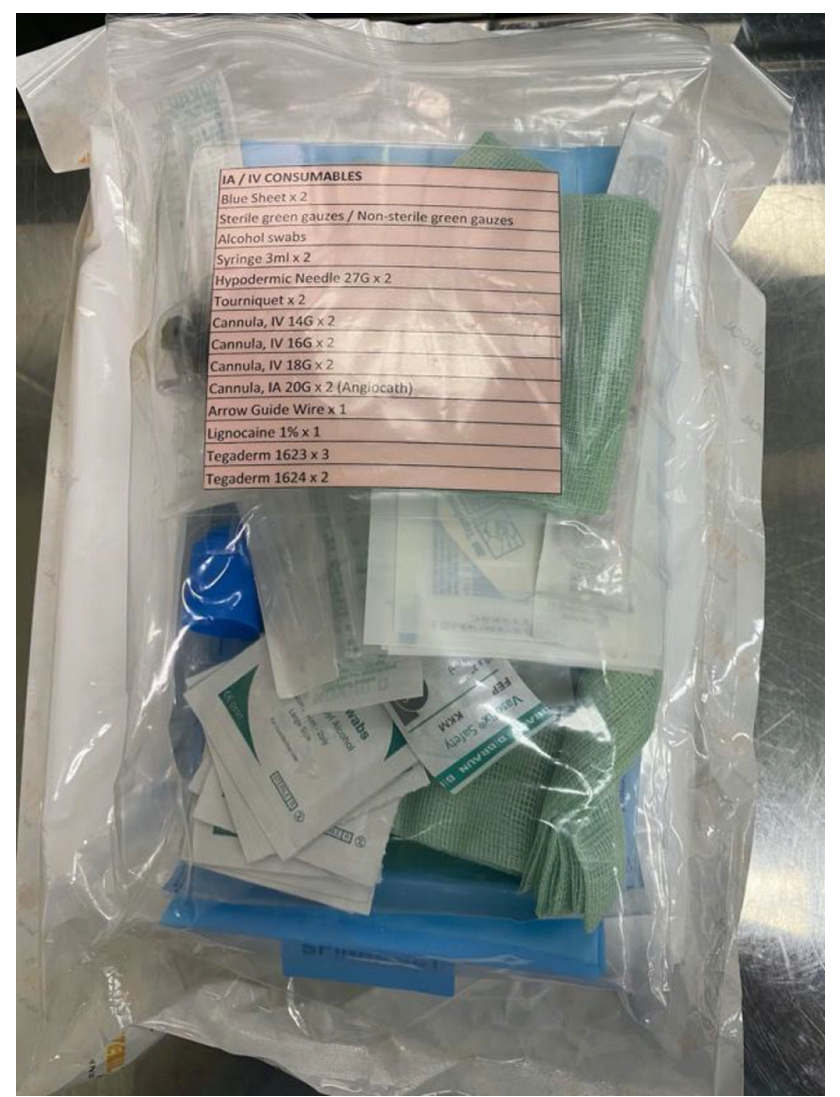

Fig. 4 Pre-packed sets of equipment

problems that were not apparent in the initial planning, such as lack of oversight and coordination, environment limitations, unsatisfactory equipment set-up, communication difficulties, lack of familiarity with protective equipment, infection control breaches, and inadequate support during crisis. These led to many downstream interventions, including appointing an OR coordinator to oversee this multi-step and multidisciplinary activation process to ensure that essential steps that may potentially compromise patient and staff safety were not missed. By rectifying deficiencies, we were able to effectively improve OR responsiveness and readiness by streamlining the ward transport process and refining the OR activation workflow. This was reflected in faster activation times with each in situ simulation.

\section{Discussion}

As part of disease containment measures, our anesthetic division implemented the above procedures in phases to decrease the risk of SARS-CoV2 transmission. In the initial phase, the emphasis was on identifying and isolating imported cases. Once local community transmission had been reported, surveillance was enhanced to identify cases, including cases with no previous travel to affected areas or previous contact with infected persons. At that stage, routine PPE was also enhanced in case of undiagnosed COVID-19. However, if there is widespread global transmission, containment will no longer be feasible and the goals will shift towards risk mitigation instead, to reduce the impact on society. ${ }^{44,45}$

Containment measures may be categorized according to the hierarchy of controls approach, ${ }^{46}$ which has been used to effectively control exposure to occupational hazards (Fig. 5).

To control exposure to infectious diseases in the healthcare environment, options for hazard control, such as elimination and substitution controls, are often limited or not feasible. Nevertheless, transmission of respiratory pathogens (such as SARS-CoV2) can often be reduced through exposure control by means of engineering, administrative controls, and PPE. ${ }^{5,28}$ Figure 6 shows the summary of the measures adopted.

Engineering controls refer to the placement of barriers between the hazard and healthcare personnel. Ideally, AIIR
Fig. 5 Hierarchy of controls to control exposure to occupational hazards. The five layers can be implemented concurrently or sequentially. To control exposure to infectious diseases in the healthcare environment, elimination and substitution controls are often limited or not feasible. Effectiveness of control measures generally decreases down the layers

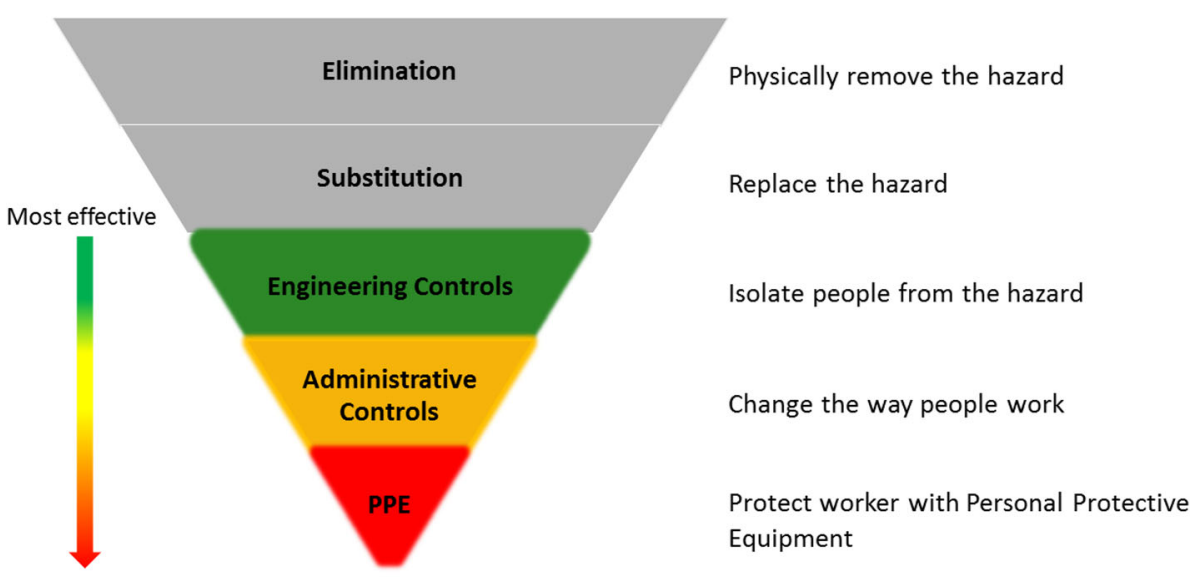

Least effective 


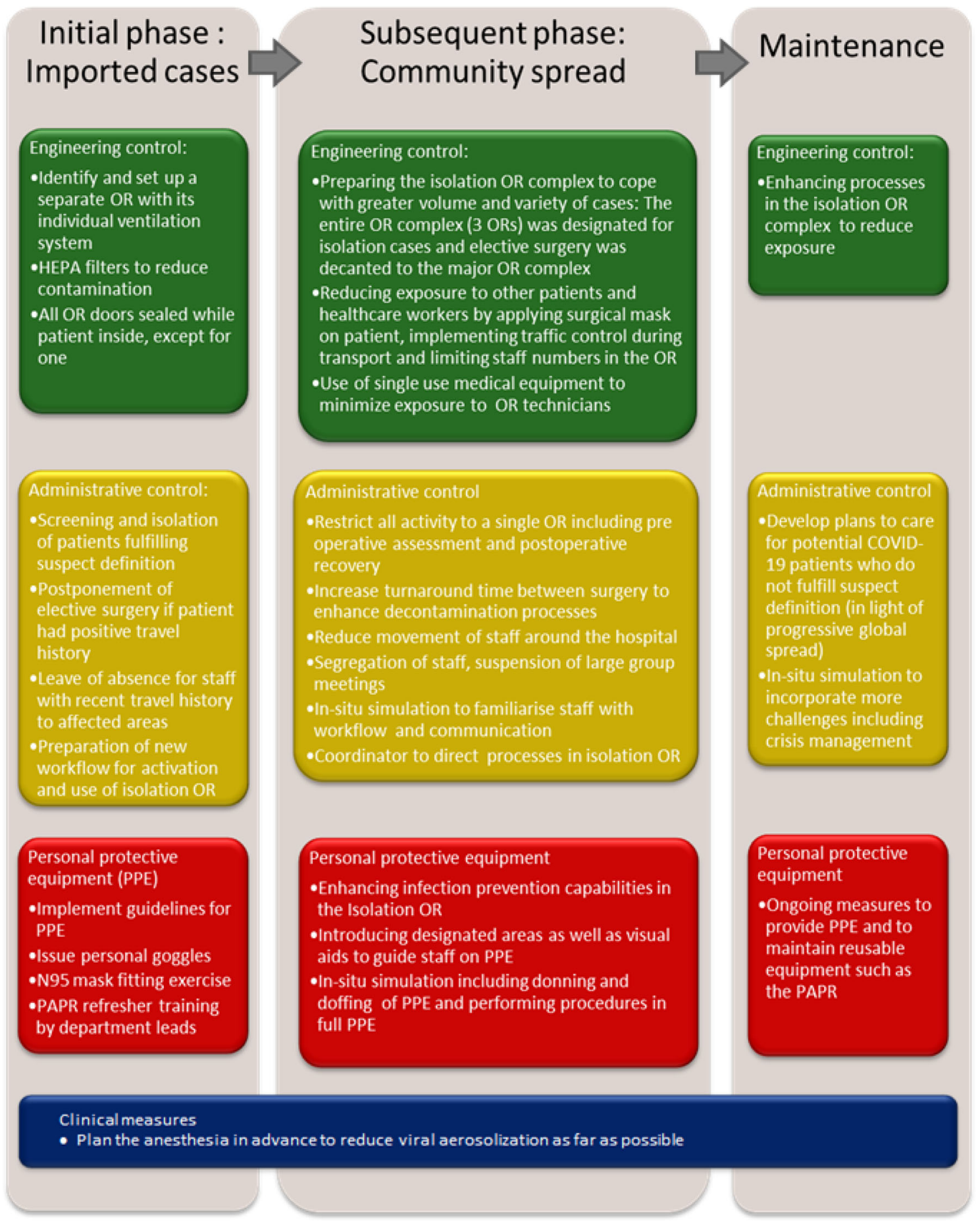

Fig. 6 Summary of the measures implemented in the operating room and anesthetic department to enhance infection prevention in a COVID-19 pandemic

should be used as ORs for surgical patients who had airborne infections. ${ }^{28}$ Nevertheless, in our institution, all the ORs are positive pressure rooms and we did not have AIIR which could be used as ORs. Therefore, a separate OR complex was set aside for surgery involving COVID19 patients. Disposable anesthetic and surgical equipment were used whenever possible to decrease the risk of virus exposure to OR sterile processing technicians. HEPA filters were used at the patient's end of the breathing circuit and also between the expiratory limb of the circuit and the anesthetic machine to decrease the risk of environmental contamination. 
Administrative controls refer to policies mandated by healthcare institutions to reduce or prevent exposure to hazards. One of the first policies implemented was to discourage unnecessary travel to high-risk areas affected by COVID-19, and to impose a leave of absence upon return from these areas. It is likely that travel restrictions in China over the Chinese New Year holiday limited the spread of infections. ${ }^{7,47}$ In the first few weeks of the outbreak, cases outside China emerged in Bangkok, Hong Kong, and Singapore-all cities with high volumes of air traffic from China. ${ }^{48}$ COVID-19 infections diagnosed in six countries were traced back to one single conference. ${ }^{49}$ At least one medical conference in Singapore was cancelled because of transmission risk.

Other administrative controls in the hospital environment include the screening and isolation of high risk patients. Location-based segregation of staff was implemented and large group meetings were suspended to reduce potential cross-infection among healthcare personnel. In a pandemic, should the numbers of COVID-19 patients increase dramatically, OR staff should be segregated into those caring for infected patients and those caring for other patients, to reduce the possibility of in-hospital transmission. ${ }^{28}$ Anesthetic preassessment, induction, and postoperative recovery of each patient should be conducted in a single OR with restricted staff numbers. $^{28}$ In situ simulation was invaluable in helping us identify latent threats and gaps in workflow. It allowed members of the operating team to understand the challenges of operating in an unfamiliar environment with additional PPE, and allowed us to identify unexpected deficiencies that were not apparent in the initial planning stage. Together with other authors who have used simulation-based training to prepare for disease outbreaks, $^{50,51}$ we highly recommend it to refine processes, enhance communication, and build staff confidence.

Personal protective equipment is the final line of protection for healthcare workers especially in the context of community transmission, as patients without known contact history may also be carriers of the virus. In line with Occupational Safety and Health Administration
Respiratory Protection Standards, all healthcare personnel were trained on the indications and proper use of PPE.

Twenty percent of anesthesiologists in our division failed fit-testing for N95 respirators $(1860,1860 \mathrm{~S}, 1870+$ by $3 \mathrm{M}^{\mathrm{TM}}$ [3M, St Paul, MN, USA]), increasing the risk of them becoming infected should they be exposed. ${ }^{52}$ Alternative respiratory protection should be made available to these staff, or they should be allocated duties away from high-risk areas. This has implications on anesthetic departments in particular, as our routine work involves aerosol-generating procedures. Staff who failed to be fitted for the N95 respirator may use the PAPR instead. In our department, they were fitted for a PAPR with a facepiece $\left(\right.$ CleanSpace $^{\mathrm{R}} \mathrm{HALO}^{\mathrm{TM}}$ ). This offers better protection than a hooded PAPR with a loose fitting facepiece. ${ }^{53}$ Sufficient PAPR devices should therefore be available to cater for different operational and staffing needs and advance consideration must be given to purchasing additional sets. Furthermore, eye protection is important because inoculation of the conjunctival surface may result in COVID-19 infection ${ }^{5,54,55}$ Goggles were therefore issued to each member of staff.

There is risk of a shortage of N95 respirators during any pandemic, especially if it becomes prolonged. Measures taken to mitigate this included earlier mentioned engineering and administrative controls to decrease the number of healthcare personnel requiring respiratory protection. Alternatives such as PAPRs may be used and practices may be introduced to extend the use of each N95 respirator. The latter include extended use and limited reuse. ${ }^{56}$ Extended use refers to the practice of wearing the same N95 respirator for repeated close contact encounters with several patients, without removing the respirator between patient encounters. Studies have shown that most healthcare personnel could tolerate wearing N95 respirators for up to eight to $12 \mathrm{hr}^{57,58}$ Nevertheless, because most healthcare workers need to take breaks during shifts to eat, drink, and use the toilet, extended use of N95 beyond four hours is unlikely in most settings. ${ }^{59}$ Re-use refers to the practice of using the same N95 respirator for multiple encounters with patients but removing it after each encounter. The Association for Professionals in Infection Control and Epidemiology

Table 1 Recommended practices for extending the use and/or re-using an N95 respirator

Avoid removing, adjusting, or touching the respirator (both outside and inside surfaces)

Discard the respirator if it becomes grossly contaminated or damaged or if breathing through it becomes difficult

Perform hand hygiene before and after handling/touching the respirator

Store the respirator in a clean, dry location to avoid contamination and maintain its integrity. It can be stored in a single-use breathable container, or hung in a designated area

Inspect the respirator and perform a seal check before each use 
position paper, developed from various guidelines (including the United States Centers for Disease Control and Prevention, Food and Drug Administration, Occupational Safety and Health Administration, WHO and the Institute of Medicine), recommend extended use over re-use. $^{60}$

For cases with highly suspected or confirmed COVID19 infection, we adopted a single-use policy for these respirators because extended use and limited re-use of these respirators carries risks, such as droplet spray contamination, degradation of filtration efficacy and mask fit with time, cross-contamination during storage, and contamination during doffing and donning of the respirators.

Nevertheless, we adopted a re-use policy for N95 respirators for cases with a low suspicion of COVID-19 infection. The recommended practices for extending the use and/or reusing a respirator can be found in Table $1 .{ }^{60}$ This includes performing hand hygiene before and after handling of the respirator; inspecting and performing a seal check before each use; avoiding the removal, adjustment, and contact with the inner and outer surfaces of the respirator; storing it in a clean dry location to avoid contamination and to maintain its integrity; and discarding the respirator if it is grossly contaminated or damaged or if breathing through it becomes difficult.

Training staff to use PPE competently is essential. In an observational study, $90 \%$ of staff did not use the correct doffing sequence or technique, or use the appropriate PPE. ${ }^{61}$ According to a survey conducted by Amrita John et al., 11 of 74 (14.9\%) physicians did not have prior training in the use of PPE. ${ }^{62}$ Emphasis must be placed on proper doffing technique and staff must be reminded not to touch their eyes, face, or mucous membranes as these may lead to self-contamination. In our institution, trainers from the Infection Control and Occupational Medicine departments were initially overwhelmed by requests to conduct PAPR training. To mitigate this, we arranged for these trainers to teach and test a small group of anesthetic consultants on the correct use of PAPR. This group then went on to teach all 180 staff in the division.

Powered air-purifying respirators have a higher protective factor than N95 respirators, ${ }^{63}$ but there is no conclusive evidence to show that PAPRs decrease the likelihood of viral transmission, especially airborne transmission. $^{36}$ The concurrent use of N95 respirators with PAPR to further decrease the risk of viral transmission may sound tempting, but there is no strong evidence of an added protective effect. ${ }^{64}$ Disadvantages of such concurrent use include increased communication difficulties, ${ }^{65}$ claustrophobic reactions, ${ }^{66}$ and increased risk of infection from doffing the additional layers of PPE (Table 2). ${ }^{67}$ It is more important to emphasize proper doffing and cleaning of PAPR for re-use to prevent contamination and cross-infection.

A recent review of 22 studies revealed that human coronaviruses such as SARS-CoV, Middle East Respiratory Syndrome (MERS) coronavirus, or endemic human coronaviruses can persist (i.e., maintain viral morphology or ability to infect cells) on inanimate surfaces such as metal, glass, or plastic for up to nine days. Nevertheless, these can be efficiently inactivated by surface disinfection procedures with $62-71 \%$ ethanol, $0.5 \%$ hydrogen peroxide or $0.1 \%$ sodium hypochlorite within one minute. ${ }^{68}$ Other biocidal agents such as $0.05-0.2 \%$ benzalkonium chloride or $0.02 \%$ chlorhexidine digluconate

Table 2 Pros and cons of powered air-purifying respirator (PAPR)

\begin{tabular}{|c|c|}
\hline Pros & Cons \\
\hline Higher protective factor than N95 respirators & $\begin{array}{l}\text { No definitive evidence that PAPR reduces likelihood of viral } \\
\text { transmission for potential airborne infections }\end{array}$ \\
\hline Provides eye protection (hooded models only) & $\begin{array}{l}\text { Inability to auscultate for heart and lung sounds (for hooded } \\
\text { PAPR) }\end{array}$ \\
\hline More comfortable to wear than N95 respirator & Challenges in communication \\
\hline Can be used if user has facial hair (not possible with N95 respirator) & Patient apprehension (especially among pediatric patients) \\
\hline Hooded models do not require fit-testing (unlike N95 respirator) & $\begin{array}{l}\text { Training on use, doffing, and care of PAPR is needed to prevent } \\
\text { contamination }\end{array}$ \\
\hline Eliminates unexpected poor N95 respirator fit & Requires decontamination after use \\
\hline Less likely to be dislodged when managing an agitated patient & More expensive than N95 respirator \\
\hline \multirow[t]{3}{*}{$\begin{array}{l}\text { PAPRs with hood may provide additional protection against contamination } \\
\text { compared with typical gear worn with N95 mask }\end{array}$} & $\begin{array}{l}\text { Inability to re-use disposable filters between patients (need large } \\
\text { supply of filters) }\end{array}$ \\
\hline & $\begin{array}{l}\text { Need to train staff repeatedly to maintain competency if not } \\
\text { frequently used }\end{array}$ \\
\hline & Risk of battery failure and inadvertent exposure \\
\hline
\end{tabular}


are less effective. The disinfection process at our institution involves cleaning of all medical devices with quaternary ammonium chloride disinfectant wipes and cleaning of the OR with sodium hypochlorite followed by hydrogen peroxide vaporization or ultraviolet-C irradiation.

The mechanical action of wiping removes organic debris. The disinfectant solution released by the wipe on the target surface is responsible for the bactericidal activity. Quaternary ammonium compounds have good cleaning and deodorization properties with a broad spectrum of biocidal and sporostatic activity, including against lipid-enveloped viruses such as coronaviruses. ${ }^{69}$ Hypochlorite is affordable, has a rapid onset, and has a large bactericidal spectrum with no toxic residues. ${ }^{69}$

Hydrogen peroxide vaporization is effective against a range of bacteria and viruses within hospital settings, ${ }^{70}$ including transmissible gastroenteritis coronavirus of pigs, a surrogate for the SARS-CoV. ${ }^{71}$ Ultraviolet-C irradiation effectively inactivates aerosolized viruses, bacteria, and fungi. ${ }^{72}$

\section{Conclusions}

Preparation for a pandemic involves considering the different levels in the hierarchy of controls as well as the different phases of the pandemic. In the OR setting, these measures include the modification of infrastructure and processes, management of staff and patients, infection prevention strategies, and clinical recommendations. The OR is a complex environment with multiple stakeholders including anesthesiologists, surgeons, nurses, OR attendants, and technicians; it can be a challenge to align the interests and concerns of all parties. Nevertheless, we believe that these containment measures are necessary to optimize the quality of care provided to COVID-19 patients and to reduce the risk of viral transmission to other patients or healthcare workers.

Acknowledgements The authors would like to acknowledge the Division of Anaesthesiology, Singapore General Hospital.

\section{Conflicts of interest None.}

Funding statement None.

Editorial responsibility This submission was handled by Dr. Hilary P. Grocott, Editor-in-Chief, Canadian Journal of Anesthesia.

\section{References}

1. World Health Organization. Statement on the second meeting of the International Health Regulations (2005) Emergency
Committee regarding the outbreak of novel coronavirus (2019nCoV). Available from URL: https://www.who.int/news-room/ detail/30-01-2020-statement-on-the-second-meeting-of-the-intern ational-health-regulations-(2005)-emergency-committee-regardingthe-outbreak-of-novel-coronavirus-(2019-ncov) (accessed March 2020).

2. Huang C, Wang $Y$, Li X, et al. Clinical features of patients infected with 2019 novel coronavirus in Wuhan. China. Lancet 2020; 395: 497-506.

3. Wang $D, H u B, H u C$, et al. Clinical characteristics of 138 hospitalized patients with, novel coronavirus-infected pneumonia in Wuhan, China. JAMA 2019; DOI: https://doi.org/10.1001/ jama.2020.1585.

4. Chen N, Zhou M, Dong X, et al. Epidemiological and clinical characteristics of 99 cases of 2019 novel coronavirus pneumonia in Wuhan, China: a descriptive study. Lancet 2020; 395: 507-13.

5. Centers for Disease Control and Prevention. Coronavirus Disease 2019 (COVID-19) Situation Summary. Available from URL: https://www.cdc.gov/coronavirus/2019-ncov/summary. html (accessed March 2020).

6. Operations Dashboard for ArcGIS. Available from URL: https:// doc.arcgis.com/fr/operations-dashboard (accessed March 2020).

7. Wu Z, McGoogan JM. Characteristics of and important lessons from the coronavirus disease, (COVID-19) outbreak in China: summary of a report of 72314 cases from the Chinese Center for Disease Control and Prevention. JAMA 2019; DOI: https://doi. org/10.1001/jama.2020.2648.

8. World Health Organization. Coronavirus disease 2019 (COVID19) Situation Report - 43. 03 March 2020. Available from URL: https://www.who.int/docs/default-source/coronaviruse/situationreports/20200303-sitrep-43-covid-19.pdf?sfvrsn=2c21c09c_2 (accessed March 2020).

9. Abdullah Z, Solamat H. Singapore confirms first case of Wuhan virus. CNA. Available from URL: https://www.channelnewsasia. com/news/singapore/wuhan-virus-pneumonia-singapore-confirmsfirst-case-12312860 (accessed March 2020).

10. Young BE, Ong SW, Kalimuddin S, et al. Epidemiologic features and clinical course of patients infected with SARS-CoV-2 in Singapore. JAMA 2020; DOI: https://doi.org/10.1001/jama.2020. 3204.

11. Ministry of Health Singapore. Confirmed cases of local transmission of novel coronavirus infection in Singapore. Available from URL: https://www.moh.gov.sg/news-highlights/ details/confirmed-cases-of-local-transmission-of-novel-coronavir us-infection-in-singapore (accessed March 2020).

12. Ministry of Health Singapore. Risk assessment raised to DORSCON Orange. 2020. Available from URL: https://www. moh.gov.sg/news-highlights/details/risk-assessment-raised-to-dor scon-orange (accessed March 2020).

13. Wong JE, Leo YS, Tan CC. COVID-19 in Singapore-current experience: critical global issues that require attention and action. JAMA 2020; DOI: https://doi.org/10.1001/jama.2020.2467.

14. World Health Organization. Q\&A on coronavirus (COVID-19). Available from URL: https://www.who.int/news-room/q-a-detail/ q-a-coronaviruses (accessed March 2020).

15. European Centre for Disease Prevention and Control. COVID19. Available from URL: https://www.ecdc.europa.eu/en/novelcoronavirus-china (accessed March 2020).

16. Centers for Disease Control and Prevention. Isolation Precautions. Available from URL: https://www.cdc.gov/ infectioncontrol/guidelines/isolation/index.html (accessed March 2020).

17. Poutanen SM, McGeer AJ. Transmission and control of SARS. Curr Infect Dis Rep 2004; 6: 220-7.

18. Yeo C, Kaushal S, Yeo D. Enteric involvement of coronaviruses: is faecal-oral transmission of SARS-CoV-2 possible? Lancet 
Gastroenterol Hepatol 2020; DOI: https://doi.org/10.1016/S24681253(20)30048-0.

19. Centers for Disease Control and Prevention. How COVID-19 spreads. Available from URL: https://www.cdc.gov/coronavirus/ 2019-ncov/about/transmission.html (accessed March 2020).

20. Scales DC, Green $K$, Chan AK, et al. Illness in intensive care staff after brief exposure to severe acute respiratory syndrome. Emerg Infect Dis 2003; 9: 1205-10.

21. Loeb M, McGeer A, Henry B, et al. SARS among critical care nurses. Toronto. Emerg Infect Dis 2004; 10: 251-5.

22. Rothe C, Schunk M, Sothmann P, et al. Transmission of 2019nCoV infection from an asymptomatic contact in Germany. N Engl J Med 2020; DOI: https://doi.org/10.1056/NEJMc2001 468.

23. Riou J, Althaus CL. Pattern of early human-to-human transmission of Wuhan, novel coronavirus (2019-nCoV), December 2019 to January 2020. Euro Surveill 2019; DOI: https://doi.org/10.2807/1560-7917.ES.2020.25.4.2000058.

24. Li $Q$, Guan $X, W u P, W$, et al. Early Transmission dynamics in Wuhan, China, of novel coronavirus-infected pneumonia. N Engl J Med 2020; DOI: https://doi.org/10.1056/nejmoa2001316.

25. Kamming D, Gardam M, Chung $F$. Anaesthesia and SARS. Br J Anaesth 2003; 90: 715-8.

26. Tan TK. How severe acute respiratory syndrome (SARS) affected the department of anaesthesia at Singapore General Hospital. Anaesth Intensive Care 2004; 32: 394-400.

27. Ter Chee VW, Khoo ML, Lee SF, Lai YC, Chin NM. Infection control measures for operative procedures in severe acute respiratory syndrome-related patients. Anesthesiology 2004; 100: 1394-8.

28. World Health Organization. Infection prevention and control of epidemic- and pandemic-prone acute respiratory diseases in health care. WHO guidelines 2007.

29. Ministry of Health Singapore. Additional precautionary measures in response to escalating global situation. Available from URL: https://www.moh.gov.sg/news-highlights/details/additional-preca utionary-measures-in-response-to-escalating-global-situation (accessed March 2020).

30. Ti, LK, Ang LS, Foong TW, $N g B S$. What we do when a COVID19 patient needs an operation: operating room preparation and guidance. Can J Anesth 2020; 67. DOI: https://doi.org/10.1007/ s12630-020-01617-4.

31. Peng PW, Wong DT, Bevan D, Gardam M. Infection control and anesthesia: lessons learned from the Toronto SARS outbreak. Can J Anesth 2003; 50: 989-97.

32. Christian MD, Loutfy M, McDonald LC, et al. Possible SARS coronavirus transmission during cardiopulmonary resuscitation. Emerg Infect Dis 2004; 10: 287-93.

33. Tompkins BM, Kerchberger JP. Special article: personal protective equipment for care of pandemic influenza patients: a training workshop for the powered air purifying respirator. Anesth Analg 2010; 111: 933-45.

34. Wilkes AR, Benbough JE, Speight SE, Harmer M. The bacterial and viral filtration performance of breathing system filters. Anaesthesia 2000; 55: 458-65.

35. Guan WJ, Ni ZY, Hu Y, et al. Clinical characteristics of coronavirus disease, in China. N Engl J Med 2019; DOI: https://doi.org/10.1056/NEJMoa2002032.

36. Wax RS, Christian MD. Practical recommendations for critical care and anesthesiology teams caring for novel coronavirus (2019-nCoV) patients. Can J Anesth 2020; DOI: https://doi.org/ 10.1007/s12630-020-01591-x.

37. Chen H, Guo J, Wang C, et al. Clinical characteristics and intrauterine vertical transmission potential of COVID-19 infection in nine pregnant women: a retrospective review of medical records. Lancet 2020; DOI: https://doi.org/10.1016/ S0140-6736(20)30360-3.
38. Favre G, Pomar L, Qi X, Nielsen-Saines K, Musso D, Baud D. Guidelines for pregnant women with suspected SARS-CoV-2 infection. Lancet Infect Dis 2020; DOI: https://doi.org/10.1016/ S1473-3099(20)30157-2.

39. Centers for Disease Control and Prevention. Coronavirus Disease 2019 (COVID-19). Interim considerations for infection prevention and control of coronavirus disease 2019 (COVID-19) in inpatient obstetric healthcare settings. Available from URL: https://www.cdc.gov/coronavirus/2019-ncov/hcp/inpatient-obstet ric-healthcare-guidance.html (accessed March 2020).

40. Kurup V, Matei $V$, Ray J. Role of in-situ simulation for training in healthcare: opportunities and challenges. Curr Opin Anaesthesiol 2017; 30: 755-60.

41. Patterson MD, Geis GL, Falcone RA, LeMaster T, Wears RL. In situ simulation: detection of safety threats and teamwork training in a high risk emergency department. BMJ Qual Saf 2013; 22: 468-77.

42. Mastoras G, Poulin C, Norman L, et al. Stress testing the resuscitation room: latent threats to patient safety identified during interprofessional in situ simulation in a Canadian Academic emergency department. AEM Educ Train 2019; DOI: https://doi.org/10.1002/aet2.10422.

43. Fent $G$, Blythe J, Farooq O, Purva $M$. In situ simulation as a tool for patient safety: a systematic review identifying how it is used and its effectiveness. BMJ Simul Technol Enhanced Learn 2015; DOI: https://doi.org/10.1136/bmjstel-2015-000065.

44. World Health Organization. Pandemic influenza preparedness and response. A WHO guidance document - 2009. Available from URL: https://apps.who.int/iris/bitstream/handle/10665/441 23/9789241547680_eng.pdf;jsessionid=1F82125A878C00D08B 9AC204EB320742? sequence $=1$ (accessed March 2020).

45. Ministry of Health Singapore. $\mathrm{MOH}$ pandemic readiness and response plan for influenza and other acute respiratory diseases April 2014. Available from URL: https://www.moh.gov.sg/docs/ librariesprovider5/diseases-updates/interim-pandemic-plan-publicver-_april-2014.pdf (accessed March 2020).

46. Centers for Disease Control and Prevention. Hierarchy of Controls - NIOSH Workplace Safety and Health Topics. Available from URL: https://www.cdc.gov/niosh/topics/hierarchy/default.html (accessed March 2020).

47. Chen S, Yang J, Yang W, Wang C, Bärnighausen T. COVID-19 control in China during mass population movements at New Year. Lancet 2020; DOI: https://doi.org/10.1016/S0140-6736(20)30421-9.

48. Bogoch II, Watts A, Thomas-Bachli A, Huber C, Kraemer MU, Khan K. Pneumonia of unknown aetiology in Wuhan, China: potential for international spread via commercial air travel. J Travel Med 2020; DOI: https://doi.org/10.1093/jtm/taaa008.

49. Vaswani K. Coronavirus: why Singapore is so vulnerable to coronavirus spread. BBC News, 13 Feb 2020. Available from URL: https://www.bbc.com/news/world-asia-51480613 (accessed March 2020).

50. Abualenain JT, Al-Alawi MM. Simulation-based training in Ebola personal protective equipment for healthcare workers: experience from King Abdulaziz University Hospital in Saudi Arabia. J Infect Public Health 2018; 11: 796-800.

51. National Academies of Sciences, Engineering, and Medicine. The Ebola Epidemic in West Africa: Proceedings of a Workshop. DC: The National Academies Press; 2016.

52. Lee $K$, Slavcev A, Nicas $M$. Respiratory protection against Mycobacterium tuberculosis: quantitative fit test outcomes for five type N95 filtering-facepiece respirators. J Occup Environ Hyg 2004; 1: 22-8.

53. Occupational Safety and Health Administration; US Department of Labor. Assigned protection factors for the revised respiratory protection standard - 2009. Available from URL: https://www.osha. gov/Publications/3352-APF-respirators.pdf (accessed March 2020). 
54. Chang D, Хu H, Rebaza A, Sharma L, Dela Cruz CS. Protecting health-care workers from subclinical coronavirus infection. Lancet Respir Med 2020; DOI: https://doi.org/10.1016/S22132600(20)30066-7.

55. Li JP, Lam DS, Chen Y, Ting DS. Novel coronavirus disease 2019 (COVID-19): the importance of recognising possible early ocular manifestation and using protective eyewear. $\mathrm{Br} \mathrm{J}$ Ophthalmol 2020; 104: 297-8.

56. Centers for Disease Control and Prevention. Recommended guidance for extended use and limited reuse of $\mathrm{n} 95$ filtering facepiece respirators in healthcare settings - NIOSH Workplace Safety and Health Topic. Available from URL: https://www.cdc. gov/niosh/topics/hcwcontrols/recommendedguidanceextuse.html (accessed March 2020).

57. Radonovich LJ Jr, Cheng J, Shenal BV, Hodgson M, Bender BS. Respirator tolerance in health care workers. JAMA 2009; 301: 36-8.

58. Rebmann T, Carrico R, Wang J. Physiologic and other effects and compliance with long-term respirator use among medical intensive care unit nurses. Am J Infect Control 2013; 41: 1218-23.

59. Fisher EM, Shaffer RE. Considerations for recommending extended use and limited reuse of filtering facepiece respirators in health care settings. J Occup Environ Hyg 2014; 11: D115-28.

60. Rebmann $T$, Alexander $S$, Bartley $J$, et al. APIC position paper: extending the use and/or reusing respiratory protection in healthcare settings during disasters. Washington, DC: APIC; 2009 .

61. Phan LT, Maita D, Mortiz DC, et al. Personal protective equipment doffing practices of healthcare workers. J Occup Environ Hyg 2019; 16: 575-81.

62. John A, Tomas ME, Cadnum JL, et al. Are health care personnel trained in correct use of personal protective equipment? Am J Infect Control 2016; 44: 840-2.

63. Board on Health Sciences Policy. Institute of Medicine. Defining PAPRs and Current Standards. DC: National Academies Press (US); 2015 .
64. Roberge RJ. Evaluation of the rationale for concurrent use of N95 filtering facepiece respirators with loose-fitting powered airpurifying respirators during aerosol-generating medical procedures. Am J Infect Control 2008; 36: 135-41.

65. Coates MJ, Jundi AS, James MR. Chemical protective clothing; a study into the ability of staff to perform lifesaving procedures. J Accid Emerg Med 2000; 17: 115-8.

66. Laird IS, Goldsmith R, Pack RJ, Vitalis A. The effect on heart rate and facial skin temperature of wearing respiratory protection at work. Ann Occup Hyg 2002; 46: 143-8.

67. Nicolle L. SARS safety and science/La science et les mesures de sécurité contre le SRAS. Can J Anesth 2003; DOI: https://doi.org/ 10.1007/BF03018360.

68. Kampf G, Todt D, Pfaender S, Steinmann E. Persistence of coronaviruses on inanimate surfaces and their inactivation with biocidal agents. J Hosp Infect 2020; DOI: https://doi.org/10.1016/ j.jhin.2020.01.022.

69. Song X, Vossebein L, Zille A. Efficacy of disinfectantimpregnated wipes used for surface disinfection in hospitals: a review. Antimicrob Resist Infect Control 2019; DOI: https://doi. org/10.1186/s13756-019-0595-2.

70. Pottage T, Richardson C, Parks S, Walker JT, Bennett AM. Evaluation of hydrogen peroxide gaseous disinfection systems to decontaminate viruses. J Hosp Infect 2010; 74: 55-61.

71. Goyal SM, Chander Y, Yezli S, Otter JA. Evaluating the virucidal efficacy of hydrogen peroxide vapour. J Hosp Infect 2014; 86: 255-9.

72. Kim $D K$, Kang $D H$. UVC LED irradiation effectively inactivates aerosolized viruses, bacteria, and fungi in a chamber-type air disinfection system. Appl Environ Microbiol 2018; DOI: https:// doi.org/10.1128/AEM.00944-18.

Publisher's Note Springer Nature remains neutral with regard to jurisdictional claims in published maps and institutional affiliations. 